\title{
El benjamín de la filosofía ante el tesoro del mesianismo revolucionario. (Una lectura de Walter Benjamin a través de algunos escritos sobre literatura infantil) ${ }^{1}$
}

\section{The Benjamin of Philosophy before the Treasure of Revolutionary Messianism. (A Reading of Walter Benjamin Through Some Writings on Children's Literature)}

\author{
Silvana Rabinovich \\ Instituto de Investigaciones Filológicas \\ Universidad Nacional Autónoma de México \\ silvanar@unam.mx
}

Resumen: Desde el inicio del quehacer filosófico, los grandes pensadores han considerado el pensamiento infantil como lo contrario a la búsqueda — seria y crítica- de la verdad. Frente a esta idea, Walter Benjamin se atreve a ver el mundo desde el punto de vista de los niños y descubrir en ello la esperanza mesiánica. A lo largo de este escrito expondré, a partir de Benjamin, formas de leer de los niños y su relación con la literatura y el juego. Luego, la lección que extrae el filósofo de esta otra manera de leer y de escribir. Propongo una relación entre la crítica benjaminiana al camino tomado por la literatura para niños avanzado el siglo xix, su crítica al imperio de la ideología del progreso propia del capitalismo y de la propuesta filosófica positivista, desde la perspectiva del mesianismo revolucionario. Finalmente, invocaré la esperanza - kafkiana- a través de unos niños que leen.

Palabras clave: infancia, juego, progreso, revolucionario, esperanza.

1 Para Cecilia y Wolf Kaufman: mi madre y su padre, mis maestros. (Ella añoraba sus años de maestra rural inspirada en Pestalozzi y me organizaba excursiones al diccionario. Él me enseñó entre risas a jugar con las raíces del hebreo bíblico.) 
Abstract: $\quad$ From the beginning of the philosophical task, great thinkers have considered children's thinking as the opposite of the - serious and critical- search for truth. Contrary to this thought, Walter Benjamin dares to see the world form children's perspective and discover the messianic hope in it. Throughout this paper I will explain, based on Benjamin, the ways children read and their relationship with literature and games. Then, I will present the lesson that the philosopher draws from this other way of reading and writing. I propose a relationship between the Benjaminian criticism to the path taken by children's literature in the late nineteenth century, his critique of the empire of the ideology of progress proper to capitalism and the positivist philosophical proposal from the perspective of revolutionary messianism. Finally, I will invoke - Kafkaesque- hope through children who read.

Keywords: childhood, game, progress, revolutionary, hope

Recibido: $\quad 3$ de marzo de 2019

Aceptado: $\quad 22$ de mayo de 2019

[...] donde juegan los niños se halla enterrado un secreto

BENJAMIN 1989: 127

\section{De filósofos y niños}

“-Dime, Sócrates, ¿tienes nodriza?” Inolvidable es la pregunta; igualmente lo es la carcajada que despierta en el lector del libro 1 de la República (343 a). La ingenuidad política de Sócrates exasperaba a Trasímaco cuando lo inquirió de esta manera sorpresiva, aclarando: "porque no te limpias los mocos, que buena falta te hace, y ni siquiera sabes por ella lo que son las ovejas y el pastor". Desde los albores de la filosofía, da la impresión de que los filósofos, buscadores del saber verdadero, se encuentran en las antípodas de la infancia y de su ingenuidad característica. Tal vez solo el asombro inicial pueda verse como una práctica que el filósofo aceptaría compartir con el niño (claro que falta saber si este último lo admite...). En cuanto a lo demás, parecería que el logos quisiera ubicarse en el extremo opuesto al de infans. ${ }^{2}$ Sin embargo, Trasímaco trata a Sócrates de mocoso (la ingenuidad no goza de buena fama

2 En latín, infans significa 'mudo' o se refiere a alguien que no tiene el don de la palabra (De Miguel 2000: 465). 
ni entre filósofos ni entre sofistas, a pesar de que estos últimos se asumen como más lúdicos que los primeros). El exabrupto reproducido en el diálogo de Platón (1984), que escenifica el distanciamiento de la infancia tomado por el filósofo, es una marca congénita de la filosofía. Esta se pretende un amor adulto por la sabiduría, exento de ingenuidades.

Quizá por el significado de su apellido, ${ }^{3}$ hay un filósofo que se atrevió a tomar en serio a la niñez. ${ }^{4}$ Walter Benjamin se acuclilla para ver el mundo a la altura de los ojos de los niños y descubrir, desde esa mirada particular, un tesoro. Theodor W. Adorno condecoró a su amigo con el título de "guardián del tesoro de la Filosofía, el príncipe de los enanos" (Adorno 2001: 73). Al abrir el arcón filosófico, en un rincón olvidado, el guardián encontró la esperanza mesiánica (que, por cierto, en las Tesis sobre el concepto de historia es retratada como un enano jorobado) (Benjamin 2008: 35).5

En las páginas que siguen, me aproximaré a la manera sensible y discreta en que Benjamin describe la forma de leer de los niños y su relación con la literatura y el juego. Luego, veremos qué lección extrae el filósofo de esta otra manera de leer y de escribir tan distinta a la que caracteriza tradicionalmente a la filosofía. Propongo una relación entre la crítica benjaminiana al derrotero tomado por la literatura para niños avanzado el siglo XIX y su crítica al imperio de la ideología del progreso propia del capitalismo y su brazo filosófico positivista desde la perspectiva del mesianismo revolucionario. Finalmente, al modo de este lúdico lector de Kafka, invocaré la esperanza — kafkiana— a través de unos niños que leen.

3 Génesis 35:18 narra el nacimiento de Benjamín que coincide con la muerte de su madre (Raquel) en el parto. En su último suspiro ella lo llamó Ben-Oní (hijo de mi vigor o de mi sufrimiento) pero su padre (Jacob) lo bautizó Ben-yamín (hijo de la diestra o del sur) y suele usarse en nuestra lengua como hijo menor y predilecto.

4 En el capítulo "Filifor forrado de niño" de la novela Ferdydurke, Witold Gombrowicz puso en evidencia la puerilidad de ciertas disputas filosóficas. En las antípodas de dicha puerilidad (arraigada en la solemnidad con que se tratan a sí mismos algunos filósofos) se encuentra la lectura benjaminiana, que - libre de prejuicios - toma en serio a la infancia. "Aun el más árido de los pedantes juega, sin saberlo, en forma pueril, no infantil; tanto más juega allí donde se muestra más pedante. Pero no recordará sus juegos" (Benjamin 1989: 94).

5 Abordé este tema detenidamente en el artículo "El enano jorobado que no fuma (o la 'teología' benjaminiana contra el opio del progreso). Reflexiones a partir de la primera Tesis sobre la historia”; la idea general es que, en la alegoría de la primera tesis benjaminiana, el autómata turco jugador del ajedrez político fuma el opio del progreso mientras que el enano que lo maneja desde debajo de la mesa no fuma y combate la ideología del progreso para ganar la partida contra el fascismo (Rabinovich 2014). 


\section{Lectores en la nieve}

Niño leyendo. En la biblioteca escolar te dan un libro. El reparto se efectúa en los cursos elementales. Solo de vez en cuando te atreves a formular un deseo. A menudo ves con envidia cómo libros ardientemente deseados van a parar a otras manos. Por fin te traían el tuyo. Durante una semana quedabas totalmente a merced de los vaivenes del texto que, suave y misterioso, denso e incesante, te iba envolviendo como un torbellino de nieve. En él entrabas con una confianza ilimitada. ¡Silencio del libro, cuyo poder de seducción era infinito! Su contenido no era tan importante. Pues la lectura coincidía aún con la época en que tú mismo inventabas en la cama tus propias historias. El niño intenta seguir sus trazas ya medio borradas. Se tapa los oídos al leer; su libro descansa sobre la mesa, demasiado alta, y una de las manos está siempre encima de la página. Para él, las aventuras del héroe se han de leer todavía entre el torbellino de letras, como figura y mensaje entre la agitación de los copos. Respira el mismo aire de los acontecimientos, y todos los personajes le empañan con su aliento. Entre ellos se pierde con mucha más facilidad que un adulto. Las aventuras y las palabras intercambiadas le afectan a un grado indecible, y, al levantarse, está enteramente cubierto por la nieve de la lectura (Benjamin 1987: 52).

La escena escolar narra la espera del que — desde su intemperie - se abre a lo inesperado. La clave está en la confianza ilimitada con la cual el niño entra en la lectura: una relación con el objeto silencioso que albergará la historia del pequeño lector de oídos tapados. La lectura se describe como la afección cuyo pulso está marcado por la respiración que —oídos adentro- suena como una tormenta. Leer es aventurarse en el torbellino de nieve y experimentar la palabra. Da la impresión de que el arrojo ante (que es otra manera de decir la confianza en) el texto es inversamente proporcional al tamaño físico de quien lo enfrenta.

Aquí la lectura está directamente relacionada con el juego. Los libros infantiles semejan a los juguetes que, tal como explica el filósofo, cuanto menos expectativas de los adultos carguen, más se prestarán para que sean los niños quienes les den vida. El mundo adultocéntrico burgués toma a los niños -improductivos - por seres productivos en potencia, y se erige en modelo a seguir. ${ }^{6}$

6 "Hemos tardado mucho en darnos cuenta de que los niños no son hombres y mujeres en escala reducida, y los muñecos muestran ese error de concepto" (Benjamin 1989: 83). 
Pero los niños no anhelan ni en los juguetes ni en los libros poder imitar a los adultos, la producción no significa nada para ellos... ${ }^{7}$ y no representan, sino que inventan. De este modo se prestan a interactuar de manera utópica con muchísimas otras cosas, que no están catalogadas como juguetes ni como libros, a las que leen y con las que juegan. El juego, al igual que la lectura infantil, guarda una relación íntima con la utopía y podemos decir, a través de la lectura de Walter Benjamin, que este campo está vedado al adulto burgués. Este último, temeroso de la acusación de Trasímaco, en la medida de lo posible - en un acto fútil— creerá haber sellado las puertas de su pasado vulnerable... infantil. Ostenta una credencial que consiste en una inflada noción de experiencia (Benjamin 1993: 93-97).

A medida que crece - por arte de esa misma escuela que le suministra los libros-, el niño va aprendiendo a relacionarse de otro modo con los libros. Paulatinamente, va dejando de interactuar, de inventar. Al modo del adivino, busca adelantarse a lo que viene, aunque de esta manera muchas veces se cierra a lo inesperado. A medida que la mesa le queda menos alta, su confianza va adquiriendo los límites que impone la crítica y por eso mismo va predisponiendo - destapando- el oído. Paradójicamente, destaparse los oídos en este caso no tiene como consecuencia una escucha atenta, sino el olfato del sabueso adiestrado para encontrar lo que buscaba. Con el tiempo, la respiración pasa a tener el lugar que ocupa en la vida cotidiana: tan vital como olvidada. La nieve, entonces, pasó: fin de la intemperie. La disposición corporal a la lectura, su hábito teatral, cede a los modos apropiados que indican cierta rigidez postural: esta asegura la distancia suficiente que evitará la ingenuidad del lector. La teatralización entra en una etapa de latencia y, sobre todo, lo que se pierde es la humildad de saberse leído por el libro, mirado por sus imágenes e interpelado por los juguetes. Benjamin evoca la ilustración en un libro infantil de un paisaje "cuyo fuego multicolor se refleja en la mirada y las mejillas de los niños inclinados sobre los libros" (Benjamin 1989: 78). En un giro copernicano de la iluminación, el niño lector es aceptado como sujeto cuando todo a su alrededor se volvió objeto iluminado por la razón. Al abrigo del circo-escuela de la lectura, el niño-tigre entre las letras de nieve se volvió domador.

7 Benjamin demuestra que la imitación es propia del juego y no del juguete (Benjamin 1989: 88). En este sentido, apoyan al Quijote en su lucha contra los molinos de viento. 


\section{Leer, escribir: jugar}

Rosquilla, pluma, pausa, queja, bagatela

Una serie de palabras de este estilo, sin conexión ni contexto, son el punto de partida de un juego que gozó de gran prestigio en la época de Biedermeier. Cada uno tenía que lograr ubicarlas en un contexto convincente sin alterar su orden. La solución era tanto más apreciada cuando más breve fuera el texto, cuantos menos elementos de unión tuviera. Este juego produce hallazgos hermosísimos, especialmente en los niños. Porque para ellos las palabras son todavía como cuevas entre las cuales conocen las vías de comunicación más extrañas. Pero tratemos ahora de representarnos la inversión del juego, observemos una oración dada como si hubiera sido construida siguiendo esta regla. Tendría que adquirir de pronto un rostro extraño y excitante a nuestra vista. Pero hay algo de esta mirada en todo acto de lectura. No solo el pueblo lee novelas de esta forma - es decir, por los nombres o las fórmulas que lo asaltan desde el texto-; también el hombre culto está al acecho de giros y palabras cuando lee y el sentido es solo el trasfondo sobre el que descansa la sombra que producen las palabras y los giros como esculturas en relieve. Esto se manifiesta en primera instancia en los textos que se denominan sagrados. Cuando se los comenta, se toman palabras como si estas hubieran sido colocadas en el texto siguiendo las reglas de este juego y como si al comentarista se le hubiera encomendado la solución. Y no cabe duda de que las frases que un niño construye a partir de las palabras se parecen más a los textos sagrados que al lenguaje cotidiano de los adultos. Al respecto, un ejemplo muestra que la combinación que hace un niño (de 12 años) de las palabras antes nombradas: "El tiempo se balancea como una rosquilla a través de la naturaleza. La pluma dibuja el paisaje y, si surge una pausa, se la rellena con lluvia. No se escuchan quejas porque no hay bagatelas" (Benjamin 2011: 157-158).

Como vimos más arriba, los niños no creen en las fronteras entre la lectura, la escritura y el juego. Podemos agregar, siguiendo este fragmento citado, que los cabalistas (tan caros a Benjamin) tampoco. Si leer implica tejer voces sueltas con los mínimos agregados posibles, los intérpretes de la tradición —al modo de los chicos - son espeleólogos que muestran el mapa de una red cavernosa sumamente intrincada que sostiene a la escritura sagrada. La confianza del lector es directamente proporcional a su arrojo y obliga a comprender que el suelo del Libro de los libros tiene la firmeza de un 
termitero. ${ }^{8}$ Isaac el Ciego, un cabalista de Girona, sostenía que el verdadero texto era la parte blanca (hoy, a la luz de la cita benjaminiana, podemos decir que se trata de las pausas llenas de lluvia). Leer equivale a arrojarse con la confianza en el propio oxígeno por un cenote para ir buceando a través de una red subterránea desconocida. Así como el intérprete moderno de la Biblia hebrea va pertrechado con una guía llamada Concordancia, ${ }^{9}$ los cabalistas no cargaban peso porque llevaban la totalidad de las palabras bíblicas en su memoria. Se internaban en los cenotes del Texto con la misma fe e iguales ejercicios respiratorios de los niños que, según recuerda el benjamín lector, son capaces de respirar "el mismo aire de los acontecimientos" (podríamos agregar en esta metáfora subacuática que lo hace con la memoria prenatal de sus tiempos intrauterinos). Y así como los lectores infantiles se dejan "empañar por el aliento de los personajes", estos hombres adultos mayores de 40 años entregados a la Cábala, desprovistos de escafandra, dejan empañar sus ojos por el aliento divino.

Formas lúdicas de la lectura, juegos de escritura. Fuera de la tradición religiosa, los poetas son los guardianes que cultivan esta memoria infantil: "Cuando los niños inventan cuentos, son escenógrafos que no admiten la censura del 'sentido”' (Benjamin 1989: 73).

Para evitar imágenes idílicas, hay una parte importante de la infancia que el filósofo no ignora, esto es, "el aspecto despótico e inhumano de los niños" (Benjamin 1989: 83), que se manifiesta claramente en la destrucción de los muñecos. Los niños no temen ni a los juguetes ni a los libros y son capaces de abolir las clases sociales con solo cambiar la indumentaria de las muñecas, modificar su peinado o desnudarlas para darles un baño. Benjamin señala un cambio importante a partir de la segunda mitad del siglo xIX, con la industrialización de los juguetes. Originariamente de construcción casera (la pelota o muñeco de trapo, el papalote, el balero, entre otros), los juguetes también fueron un subproducto de distintas industrias artesanales (que se elaboraban con las sobras del material, por ejemplo: madera, cera, confitura o metal). Su industrialización independiente corre por cuenta de los modos

8 Hoy comprendo el chiste de mi abuelo (mi primer Maestro de Biblia hebrea) cuando me decía que el queso gruyere vale por el peso de sus agujeros.

9 Elaborada en su versión más completa por Salomón Mandelkern (Leipzig, 1896), cuyo antecedente es la Concordancia de la Biblia hebrea, que fue elaborada por el rabino provenzal Isaac Mardoqueo Natán, data de 1448; esta obra detalla cada vocablo que aparece en el Libro según su lugar de aparición y su sentido. 
de producción capitalista, que apostaron a su valor de cambio por el tamaño, en detrimento de la sencillez y delicadeza. En la industria del juguete el filósofo lee una alegría forzada, nacida de una conciencia de culpa del capital encarnado en la mercancía (Benjamin 1989: 91). De esto tampoco se salvaron los libros. El crítico alega:

¿Solo ahora se le da al niño su propio cuarto para jugar, una biblioteca donde pueda guardar sus libros separadamente de los que leen sus padres? No cabe duda, los tomos antiguos, con sus formatos pequeños, exigían mucho más entrañablemente la presencia de la madre. Los modernos tomos en cuarto, con su insulsa y estirada ternura, están destinados más bien a hacer olvidar su ausencia. Se inicia una emancipación del juguete; cuanto más se impone la industrialización, tanto más se sustrae al control de la familia, volviéndose cada vez más extraño, tanto para los niños como para los padres (Benjamin 1989: 86-87).

\section{La promesa mesiánica: de-crecer}

Verdaderamente revolucionaria es la señal secreta de lo venidero que se revela en el gesto infantil.

BENJAMIN 1989: 106

Leamos (juguemos): si la promesa de la pedagogía burguesa se basa en que los niños necesitan a los adultos para imitarlos y, en contraparte, estos condescienden a interpretarlos, su empeño consiste en volver promisorio el crecimiento. El capitalismo tiene una fe desmedida en la ilusión del crecimiento económico, que es el ensanchamiento del capital y la acumulación. La educación que le corresponde, basada en la acumulación de información, enarbola la promesa de crecer. Sin embargo, Benjamin le opone una promesa mesiánica, que propone un movimiento contrario: decrecer. El decrecimiento económico (Latouche 2008), del que cada día se escucha más como forma de resistencia, en las páginas del filósofo sobre la infancia encuentran su traducción al campo de la educación. ${ }^{10}$ Decrecer como promesa, en su traducción

1o No es casual que los orígenes del decrecimiento económico se atribuyan a un movimiento del siglo xIx llamado "ludismo", no por referirse al juego (se atribuye a un tal Ned Ludd quien, según se cuenta, en el pasado rompió unos telares inspirando a un movimiento de artesanos contra la industrialización), pero - si somos fieles a la propuesta benjaminiana de lectura lúdica — ¿cómo no atrevernos a relacionarlos aquí? 
educativa, equivaldría no solo a reducir las cantidades y tamaños en el consumismo cultural, ${ }^{11}$ sino también a rememorar aquel tiempo en que la mesa donde se encontraba el libro era más alta que nosotros. Tomarse en serio el juego en el acto de leer, bucear como los cabalistas, cantar como los poetas: con Manoel de Barros (2013: 10), aprender a reconocer en los niños la capacidad de pronunciar aquellas cosas que no tienen nombre. Como hace el eterno benjamín de los filósofos: ponerse de cuclillas para auscultar en el arcón filosófico los arcanos aterradores de la promesa mesiánica. El terror mesiánico se puede reconocer en la descripción de un pequeño lector atormentado, no de uno feliz que se siente cobijado por el libro. La lectura de infancia se describe como un deporte extremo.

En las Tesis sobre el concepto de historia, Benjamin nos dejará atónitos ante una imagen igualmente desconcertante del Paraíso, del cual proviene el huracán del progreso. Todo indicaría que el origen endemoniado de esta tormenta debería hallase en el Infierno; sin embargo, el filósofo prefiere evocar la violenta expulsión del Edén. ${ }^{12}$ El Angelus Novus de Paul Klee, evocado en la tesis IX — conocido como el ángel de la historia—, a la manera de los niños, combina la ternura melancólica con la violencia de los querubines apostados en la entrada del Edén que se encuentran armados para impedir el retorno de los exiliados. Benjamin atribuye a Klee el haber captado "el aspecto despótico e inhumano de los niños", capaces de cometer — como cita— "atentados terroristas en miniatura” (Benjamin 1989: 83). Algo de esto expresó el escultor Anselm Kiefer en su instalación "Angelus Novus: amapola y memoria”, que en el Museo Israel de Jerusalén exhibió un avión de plomo cubierto de libros metálicos con amapolas y semillas apuntando a la obra de Klee.13 Avión de guerra, querubín metálico. Otra vez el amasijo mesiánico de promesa y terror.

Los escritos de Benjamin sobre la infancia, sin edulcorantes, desenmascaran la pobre experiencia del capitalismo adultocéntrico y su pedagogía colo-

${ }^{11}$ "Cada vez más, tanto el escritor como el ilustrador se dirigen al niño a través del medio deshonesto de las preocupaciones y las modas del día. Anida en las estampas un gesto empalagoso que no corresponde al niño, sino a las ideas corrompidas que de él suelen hacerse. Su forma pierde la noble sencillez y se vuelve pesada" (Benjamin 1989: 71).

${ }_{12}$ El video Angelus Novus, de Lukas y Verena Fentross (2005), muestra algo de esta violencia. $C f$. <https://www.youtube.com/watch?v=mpWuouIxFGU>, consultado por última vez el 14 de mayo de 2019.

13 El nombre de la instalación, que vi en enero de 2006 en una salita del museo, alude sin duda a Benjamin con Paul Celan (Ben-Meir, 2009). 
nial (Benjamin 1989: 131-133). Los querubines benjaminianos cuentan con dos armas lúdicas (¿ludistas?) para ahuyentar la imposición burguesa de crecer: la exageración en el juego y la repetición de la narración (Benjamin 1989: 93 y 137).

\section{¡Alerta! \\ Niños de la intemperie leyendo las intemperancias de su lengua}

No había nada de ejemplar en Pestalozzi. Lo que él ofrecía a esos niños sin los cuales no podía vivir, no era su ejemplo, sino su mano [...]. Esa mano siempre estaba dispuesta, ya ayudando en el juego o el trabajo, ya acariciando de improviso la frente de un niño al pasar. Mucho de ello lo encontramos en su doctrina, pero lo mejor se halla en la práctica a la que dedicó en Iferten, con toda exclusividad, sus últimas energías (Benjamin 1989: 142).

Volvamos a la lectura infantil, esa aventura nívea que arroja al joven lector a la intemperie. Durante la experiencia de Pestalozzi en Iferten, donde el filósofo vio "un permanente congreso pedagógico", el exterior era un escenario esencial donde se desarrollaba la educación. Con el pedagogo, en el acto de lectura participaba el cuerpo. La gestualidad, tan valorada por Benjamin en el teatro infantil, era parte integral de una educación inquieta. Pedagogía inquietante para los parámetros burgueses, amparados en los valores del Estado nacional, que tanto teme a esa costumbre de intemperie llamada nomadismo. El aprendizaje que incluía los gestos anhelaba volver a encontrar la escuelita de niños pobres (Benjamin 1989: 141). Consciente de las trampas del adultocentrismo burgués que con su pedagogía ejemplar solo induce a la egolatría, el Maestro enseñaba tendiendo su mano. Este gesto educador tiene muchos sentidos: la mano se tiende abierta para acariciar o ayudar, pero el tacto - y en esto la caricia es paradigmática- no distingue entre lo que da y lo que recibe. Por eso el gesto enseñante de Pestalozzi, abierto a lo inesperado (y en ese sentido, mesiánico), tiene algo de la lectura infantil en la tormenta de nieve. Al modo del niño lector ante el libro, el Maestro tiende su mano con una confianza ilimitada. Sin confianza no hay educación sino mera transmisión de datos: confía el que enseña, confía el que aprende y por la vía de la confianza los papeles se intercambian. Pero confiar ¿no es cosa de ingenuos? La ingenuidad y la utopía siempre fueron confidentes. He aquí la señal secre- 
ta de lo venidero revelada en el gesto infantil que el Maestro captó: decrecer, reconocerse vulnerable (no intercambiar saberes, sino perplejidades).

Quisiera actualizar la experiencia benjaminiana del niño leyendo a propósito de un video filmado el 8 de abril de 2015, con motivo del Día Internacional del Pueblo Gitano. ${ }^{14}$ En él los hijos del pueblo nómade aparecen leyendo en el diccionario las acepciones de gitano. Luego de entregarse con confianza a la lectura, la inquietud de los pequeños lectores se hace notar ante el miedo a la alteridad (que es el miedo del Estado ante los nómades) expresado por nuestro idioma con una agresión. ¿Cómo puede una autoridad sobre la lengua permitirse definir a sus hijos, en una de sus acepciones, como trapaceros? ¿Acaso la autoridad no está destinada a cuidar a quienes se encuentran bajo su tutela?

El niño abre el diccionario y lo sorprende un proyectil. Si nos acuclillamos junto al benjamín de la filosofía, en el gesto del pequeño lector se nos revelará la mesiánica - revolucionaria - "señal secreta de lo venidero."

\section{Bibliografía}

Adorno, Theodor (2001). Sobre Walter Benjamin. Trad. Carlos Fortea. Madrid, Cátedra.

Ben-Meir, Kobi (2009). "Dialectics of Redemption. The Angel of History: Poppy and Memory". Artículo en línea disponible en <https://ef.huji.ac.il/publications/dialectics-redemption-anselm-kiefer\% $\mathrm{C}_{2} \% \mathrm{~B}_{4}$ s-angel-histry-poppy-and-memory>, consultado por última vez el 28 de noviembre de 2015.

Benjamin, Walter (1987). Dirección única. Trad. Juan J. del Solar y Mercedes Allendesalazar. Madrid, Alfaguara.

Benjamin, Walter (1989). Escritos. La literatura infantil, los niños y los jóvenes. Trad. Juan J. Thomas. Buenos Aires, Nueva Visión.

Benjamin, Walter (1993). La metafísica de la juventud. Trad. Luis Martínez Velasco. Barcelona, Paidós/ICE UAB.

Benjamin, Walter (2008). Tesis sobre la historia y otros fragmentos. Trad. Bolívar Echeverría. México, Ítaca/UACM.

14 Grabación realizada conjuntamente por las entidades que forman parte del Consejo Estatal del Pueblo Gitano (a las cuales se suma el Instituto de Cultura Gitana) y que se centra en la polémica generada con la nueva edición impresa del diccionario de la Real Academia Española de la Lengua a propósito de la definición de gitano. Según explican los realizadores, tras el compromiso de la Real Academia de revisar las acepciones peyorativas tales como "que estafa u obra con engaño", esta fue sustituida por trapacero. <https://www.youtube.com/watch?v=ZeexUKauotc>, consultado por última vez el 14 de mayo de 2019. 
Benjamin, Walter (2011). Denkbilder. Epifanías en viajes. Trad. Susana Mayer. Buenos Aires, El Cuenco de Plata.

De Barros, M. (2013). O libro das ignorãnças. São Paulo, LeYa.

De Miguel, R. (200o). Nuevo Diccionario Latino-Español Etimológico. Madrid, Visor.

Latouche, S, (2008). La apuesta por el decrecimiento. ¿Cómo salir del imaginario dominante? Barcelona, Icaria/ Antrazyt.

Platón (1984). La República. Trad. Antonio Camarero. Buenos Aires, Eudeba.

RABINOVICH, Silvana (2014). "El enano jorobado que no fuma (o la 'teología' benjaminiana contra el opio del progreso). Reflexiones a partir de la primera Tesis sobre la historia”, Revista En-claves del Pensamiento, vol. VIII, núm. 16 (julio-diciembre): 203-218.

\section{Silvana Rabinovich}

Doctora en Filosofía, investigadora en el Seminario de Hermenéutica del Instituto de Investigaciones Filológicas de la UNAM, tutora en el Posgrado en Filosofía de la Facultad de Filosofía y Letras de la UNAM, es responsable del Proyecto PAPIIT IN 401119 "Heteronomías de la justicia: territorialidades nómadas”. На publicado, entre otros: La Biblia y el drone: sobre usos y abusos de figuras bíblicas en el discurso político de Israel (2013), Heteronomías de la lectura (2013), Interpretaciones de la heteronomía (2018), así como Retornos del Discurso del "Indio" (para Mahmud Darwish) (2018), como editora, y Heteronomías de la justicia: de exilios y utopías, como coeditora (en prensa). 